\title{
Effect of temperature on the concentration explosion limits of combustible liquids
}

\author{
P. Lepík ${ }^{1}$, J. Serafín ${ }^{1}$, M. Mynarz ${ }^{2}$ \& J. Drgáčová ${ }^{2}$ \\ ${ }^{I}$ Department of Safety Management, Faculty of Safety Engineering, \\ $V \check{S} B$ - Technical University of Ostrava, Czech Republic \\ ${ }^{2}$ Department of Fire Protection, Faculty of Safety Engineering, \\ $V \check{S} B$ - Technical University of Ostrava, Czech Republic
}

\begin{abstract}
The contribution is focused on the theoretical calculations of the influence of the temperature on the concentration explosive limits of flammable liquids using empirical formulas. The first part of the paper is concerned with the theoretical basis of computation according to empirical formulas. The other part deals with experimental verification of the theoretical assumption of the calculation of the influence of the temperature on the concentration explosive limits of flammable liquids.
\end{abstract}

Keywords: combustible liquids, concentration explosive limits, effect of temperature,

\section{Introduction}

Flammable liquids occur across the whole spectrum of industrial production. As a result of technology innovations and of expansion of production the amount of used flammable liquids increases. Along with this aspect the risk also increases connected with flammable liquids application, among which belongs, inter alia, explosion. Explosion is in many workplaces underestimated and an insufficient attention is paid to it, even if its after-effects, material, financial and last but not least, loss of lives, can be considerable. The aim of explosion suppression safety is to design an effective protection. To design the protection effectively it is necessary to know all the aspects that may influence the potential explosion. One of these aspects is temperature. Higher temperature may occur for example by drying processes with higher temperature. With increasing initial 
temperature the area of explosibility widens. Lower explosive limit decreases and higher explosive limit increases. The dependence is linear but the slope of the line is not the same for all flammable liquids.

\section{Empirical determination of effect of temperature on concentration explosive limits}

For approximate determination of concentration explosive limits of vapors of flammable liquids, some empirically made equations can be used. Gorjačev and Kluban [2] express the effect of temperature on concentration explosive limits of flammable liquids by eqns (1) and (2). Barktnecht [1] expresses the effect of temperature on concentration explosive limits of flammable vapors and gases of flammable liquids by eqns (3) and (4).

$$
\begin{aligned}
& L E L_{T}=L E L_{293} \cdot\left(1-\frac{T-293}{1260}\right) \\
& U E L_{T}=U E L_{293} \cdot\left(1+\frac{T-293}{800}\right)
\end{aligned}
$$

where:

- $L E L_{T}$ lower explosive limit by the temperature of $\mathrm{T}$ in vol. \%,

- $U E L_{T}$ upper explosive limit by the temperature of $\mathrm{T}$ in vol. \%,

- $L E L_{293}$ lower explosive limit by the temperature of $293 \mathrm{~K}$ in vol. \%,

- $U E L_{293}$ upper explosive limit by the temperature of $293 \mathrm{~K}$ in vol. \%,

- $T$ operating temperature in $\mathrm{K}$.

$$
\begin{aligned}
& L E L_{t}=L E L_{20^{\circ} \mathrm{C}} \cdot[1-0,0011 \cdot(t-20)] \\
& U E L_{t}=U E L_{20^{\circ} \mathrm{C}} \cdot[1+0,00214 \cdot(t-20)]
\end{aligned}
$$

where:

- $L E L_{t} \quad$ lower explosive limit by the temperature of $\mathrm{t}$ in vol. $\%$,

- $U E L_{t} \quad$ upper explosive limit by the temperature of $\mathrm{t}$ in vol. \%,

- $L E L_{20^{\circ} \mathrm{C}}$ lower explosive limit by the temperature of $20^{\circ} \mathrm{C}$ in vol. $\%$,

- $U E L_{20^{\circ} \mathrm{C}}$ upper explosive limit by the temperature of $20^{\circ} \mathrm{C}$ in vol. $\%$,

- $\mathrm{t} \quad$ operating temperature in ${ }^{\circ} \mathrm{C}$.

\section{Description of test device}

For experimental determination of effect of temperature on concentration explosive limits of vapors of flammable liquids, an explosive test chamber VK20 was used. Its scheme and photo is shown in Figures 1 and 2. It is a stainless 
steel cylindrical vessel of the 201 capacity. This test device serves to determine both concentration and temperature explosive limits.

1 inner shell

2 outer shell

3 outer heating spiral

4 evapor. basin stand

5 inner heating spiral

6 mixer
7 electric engine

8 ignition electrodes

9 chemical igniter

10 cover

11 thermocouple

12 bushings
13 digital thermometer

14 control devices of

15 outer and inner spiral

16 control panel

17 computer

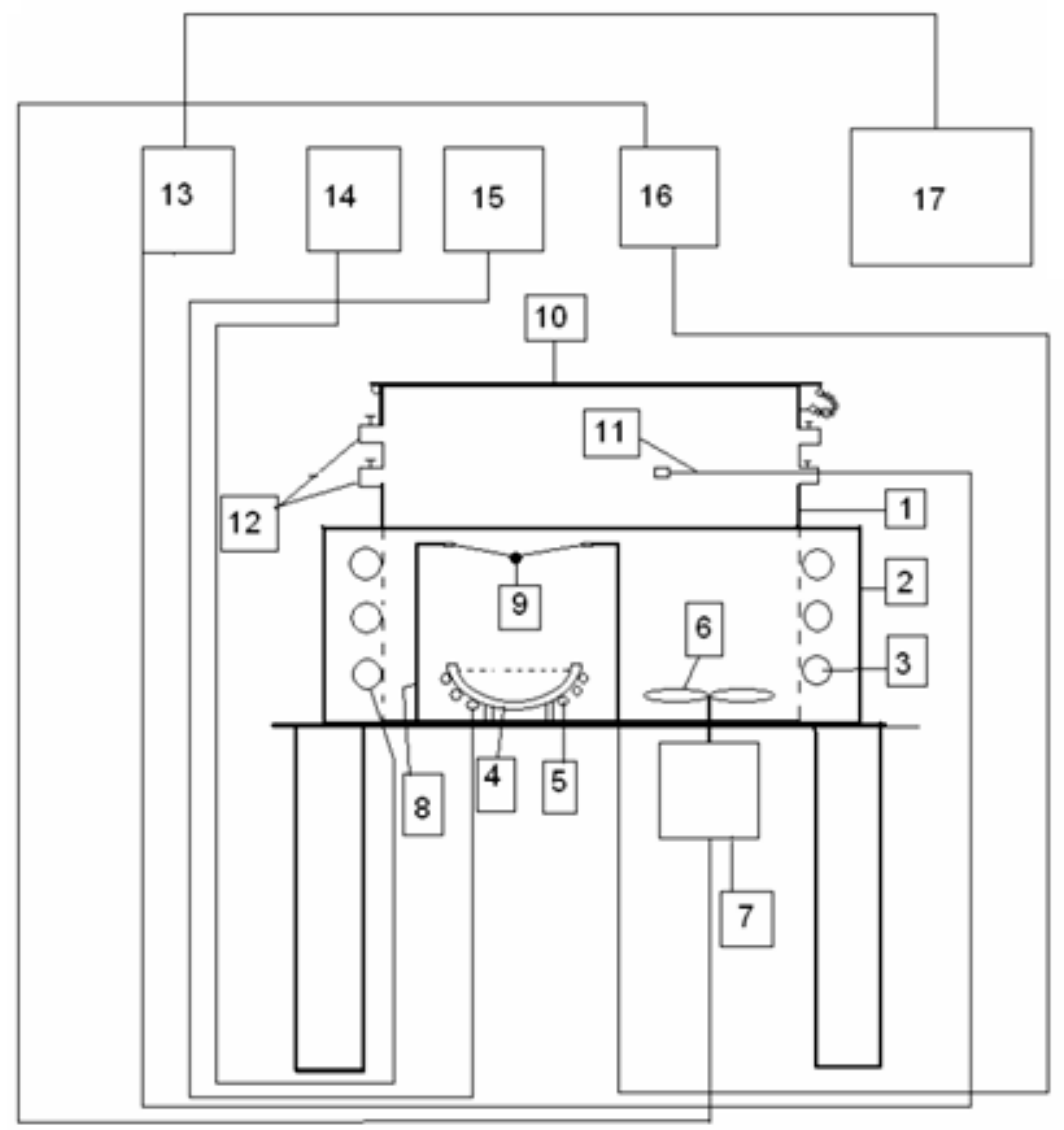

Figure 1: $\quad$ Scheme of the explosive test chamber VK-20 [3]. 


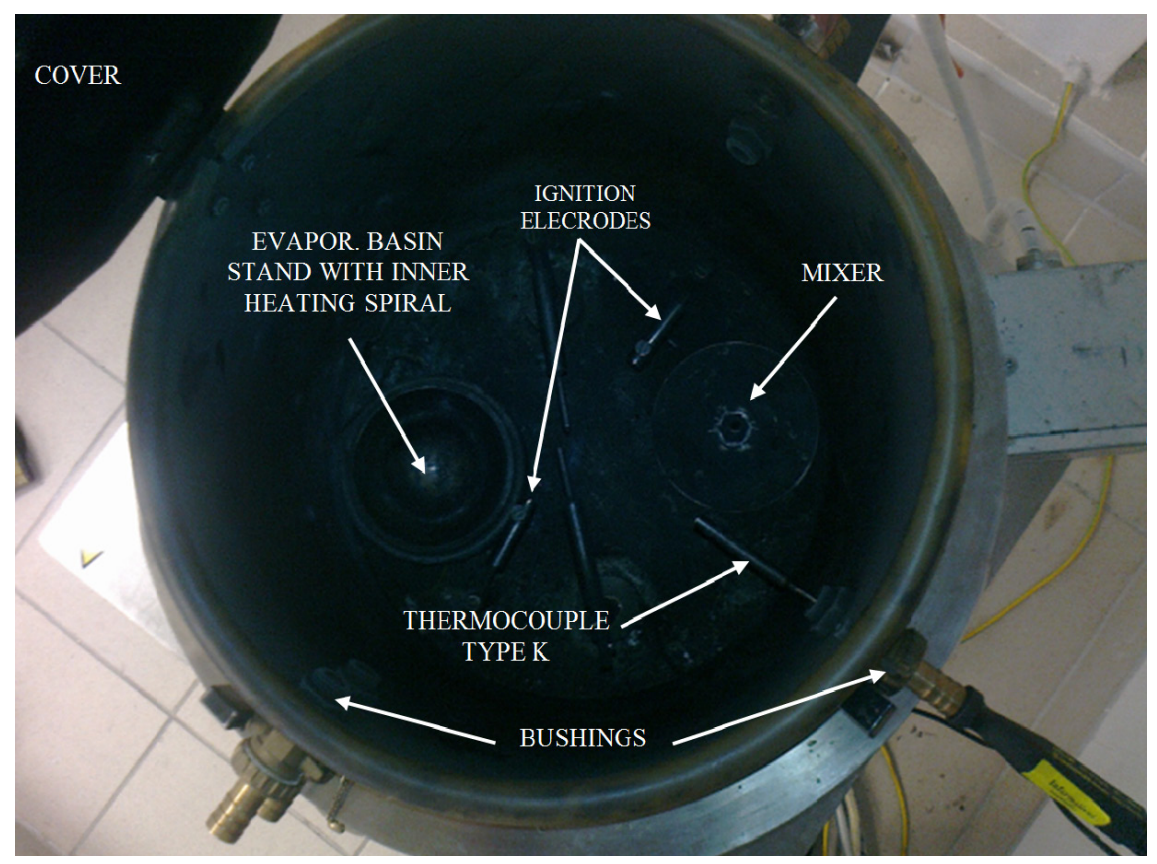

Figure 2: $\quad$ Photo VK - 20 [3].

\section{Experimental measurement}

For the experimental measurement, three samples of flammable liquids, namely industrial alcohol, acetone and toluene, were chosen. These liquids were chosen because of their different explosive range. First of all, it was necessary to determine the quantity of flammable liquid, which is needed to be placed to evaporation basin to ensure the required concentration in the explosive test chamber after evaporation. Before each measurement it was necessary to determine the time that would be adequate for evaporation of inserted amount of sample of flammable liquid. Chemical igniter with ignition energy of $86 \mathrm{~J}$ was used as an ignition source.

For evaluation of whether the explosion happened or not it was necessary first to measure the temperature rise that was caused by activating of only chemical igniter alone. During measurement, the evaluation was made on the basis of the temperature rise. For the temperature rise higher than rise caused by activating of the igniter alone, the experiment was judged as positive - the explosion happened. The measurement of effect of temperature on concentration explosive limits was taken at temperatures from $50^{\circ} \mathrm{C}$ to $170^{\circ} \mathrm{C}$ with an interval of $15^{\circ} \mathrm{C}$.

\subsection{Measuring procedure}

The explosive test chamber was heated up to the required temperature. Chemical igniter was placed between ignition electrodes and a sample of flammable liquid 
of required amount corresponding to required concentration was put into the evaporating basin. Afterwards, the explosive test chamber was covered by aluminium foil which prevents the release of vapors of flammable liquid and lowers the temperature losses. Then it was necessary to wait until the liquid is evaporated completely. Chamber volume had to be mixed by the mixer for ensuring the mixture homogeneity. After evaporation of liquid, ignition was executed and testing was assessed following measured temperature rise. The measurement was considered as confirmed in the case of two concordant results for given concentration. For the case of two different results, the third measurement was taken and then the explosibility of the concentration was confirmed or denied.

\subsection{Values determined by empirical equations}

The effect of temperature on concentration explosive limits was calculated by empirical eqns (1) and (2) of Gorjačev and Kluban [2] and empirical eqns (3) and (4) of Barktnecht [1]. The resultant values for the selected samples of flammable liquids are listed in Table 1.

Table 1: Values of concentration limits calculated by empirical equations [3].

\begin{tabular}{|c|c|c|c|c|c|c|c|c|c|}
\hline Temperature & 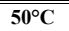 & $\overline{66^{\circ} \mathrm{C}}$ & $880^{\circ} \mathrm{C}$ & $99^{\circ} \mathrm{C}$ & $11^{110^{\circ} \mathrm{C}}$ & $\overline{125^{\circ} \mathrm{C}}$ & 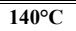 & $155^{\circ} \mathrm{C}$ & 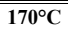 \\
\hline \multicolumn{10}{|c|}{ INDUSTRIAL ALCOHOL } \\
\hline \multicolumn{10}{|l|}{ Gorjačev } \\
\hline LEL [vol. \%] & 3,81 & 3,76 & 3,71 & 3,67 & 3,62 & 3,57 & 3,53 & 3,48 & 3,44 \\
\hline UEL [vol. \%] & 21,27 & 21,66 & 22,04 & 22,43 & 22,81 & 23,19 & 23,58 & 23,96 & 24,35 \\
\hline \multicolumn{10}{|l|}{ Bartknecht } \\
\hline LEL [vol. \%] & 3,77 & 3,71 & 3,64 & 3,58 & 3,51 & 3,45 & 3,39 & 3,32 & 3,26 \\
\hline UEL [vol. \%] & 21,82 & 22,47 & 23,13 & 23,79 & 24,45 & 25,11 & 25,76 & 26,42 & 27,08 \\
\hline \multicolumn{10}{|c|}{ ACETONE } \\
\hline \multicolumn{10}{|l|}{ Gorjačev } \\
\hline LEL [vol. \%] & 2,54 & 2,51 & 2,48 & 2,44 & 2,41 & 2,38 & 2,35 & 2,32 & 2,29 \\
\hline UEL [vol. \%] & 13,49 & 13,73 & 13,98 & 14,22 & 14,46 & 14,71 & 14,95 & 15,20 & 15,44 \\
\hline \multicolumn{10}{|l|}{ Bartknecht } \\
\hline LEL [vol. \%] & 2,51 & 2,47 & 2,43 & 2,39 & 2,34 & 2,30 & 2,26 & 2,21 & 2,17 \\
\hline UEL [vol. \%] & 13,83 & 14,25 & 14,67 & 15,09 & 15,50 & 15,92 & 16,34 & 16,76 & 17,17 \\
\hline \multicolumn{10}{|c|}{ "TOLUENE } \\
\hline \multicolumn{10}{|l|}{ Gorjačev } \\
\hline LEL [vol. \%] & 1,07 & 1,06 & 1,05 & 1,03 & 1,02 & 1,01 & 1,00 & 0,98 & 0,97 \\
\hline UEL [vol. \%] & 7,37 & 7,50 & 7,63 & 7,77 & 7,90 & 8,03 & 8,17 & 8,30 & 8,43 \\
\hline \multicolumn{10}{|l|}{ Bartknecht } \\
\hline LEL [vol. \%] & 1,06 & 1,05 & 1,03 & 1,01 & 0,99 & 0,97 & 0,95 & 0,94 & 0,92 \\
\hline UEL [vol. \%] & 7,56 & 7,78 & 8,01 & 8,24 & 8,47 & 8,70 & 8,92 & 9,15 & 9,38 \\
\hline
\end{tabular}

\subsection{Experimentally determined values}

For chosen samples of flammable liquids, the values measured by experiment in the explosive test chamber VK -20 are listed in Table 2. 
Table 2: $\quad$ Experimentally measured values of concentration limits [3].

\begin{tabular}{|c|c|c|c|c|c|c|c|c|c|}
\hline Temperature & $5^{\circ}{ }^{\circ} \mathrm{C}$ & $65^{\circ} \mathrm{C}$ & $80^{\circ} \mathrm{C}$ & $95^{\circ} \mathrm{C}$ & $110^{\circ} \mathrm{C}$ & $125^{\circ} \mathrm{C}$ & $140^{\circ} \mathrm{C}$ & $155^{\circ} \mathrm{C}$ & $170^{\circ} \mathrm{C}$ \\
\hline \multicolumn{10}{|c|}{ INDUSTRIAL ALCOHOL } \\
\hline$\overline{\text { LEL [vol. \%] }}$ & 3,5 & 3,5 & 3,5 & 3,5 & 3,3 & 3,3 & 3,3 & $\begin{array}{l}3,0 \\
, 0\end{array}$ & 3,0 \\
\hline UEL [vol. \%] & 23,0 & 23,5 & 24,5 & 25,0 & 26,0 & 26,5 & 27,0 & 27,5 & 28,0 \\
\hline \multicolumn{10}{|c|}{ ACETONE } \\
\hline LEL [vol. \%] & 2,8 & 2,5 & 2,5 & 2,5 & 2,5 & 2,3 & 2,3 & 2,3 & 2,3 \\
\hline UEL [vol. \%] & 15,0 & 15,0 & 15,5 & 16,0 & 16,0 & 16,5 & 17,5 & 17,5 & 18,0 \\
\hline \multicolumn{10}{|c|}{ TOLUENE } \\
\hline LEL [vol. \%] & 1,1 & 1,1 & 1,1 & 1,0 & 1,0 & 1,0 & 1,0 & 1,0 & 1,0 \\
\hline UEL [vol. \%] & 8,5 & 8,5 & 9,0 & 9,5 & 9,5 & 9,5 & 10,0 & 10,0 & 10,5 \\
\hline
\end{tabular}

\subsection{Evaluation of empirical and experimental values}

This section compares the experimentally measured data with the data calculated by the equations of $[1,2]$. For each of evaluated substance, two graphs are presented showing the effect of temperature on the upper and lower explosive limit.

\subsubsection{Industrial alcohol}

The effect of temperature on upper and lower explosive limit of industrial alcohol can be seen in Figures 3 and 4. From the graph it is evident that the experimentally determined values of upper explosive limit in the given temperature range are higher than values determined by the empirical eqns (2) and (4). Experimentally determined values of lower explosive limit within the given temperature range are below values determined from the eqns (1) and (3). Thus, the calculated temperatures lie in the explosion range determined from the experimental values.

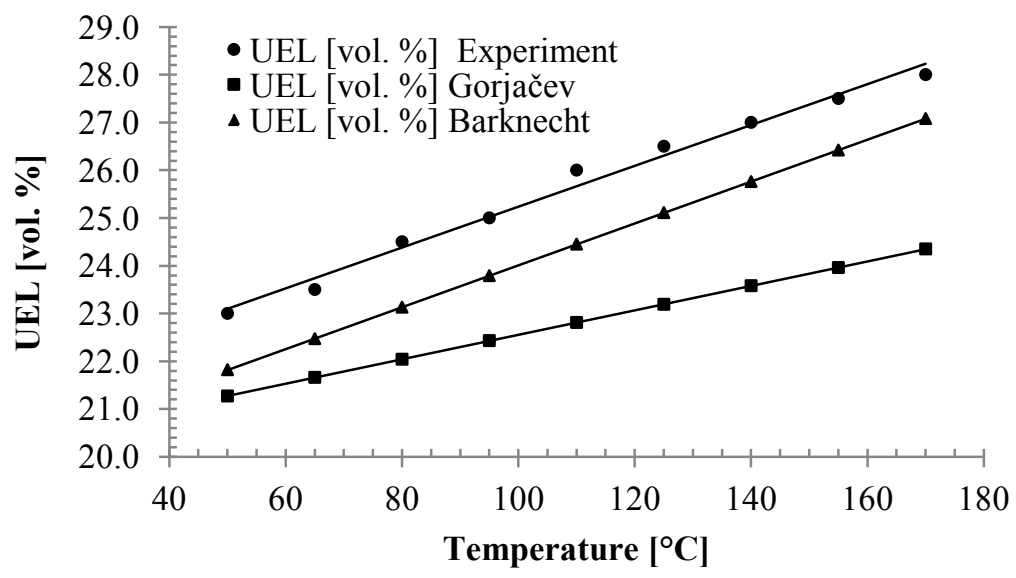

Figure 3: Graph of effect of temperature on upper explosive limit of industrial alcohol. 


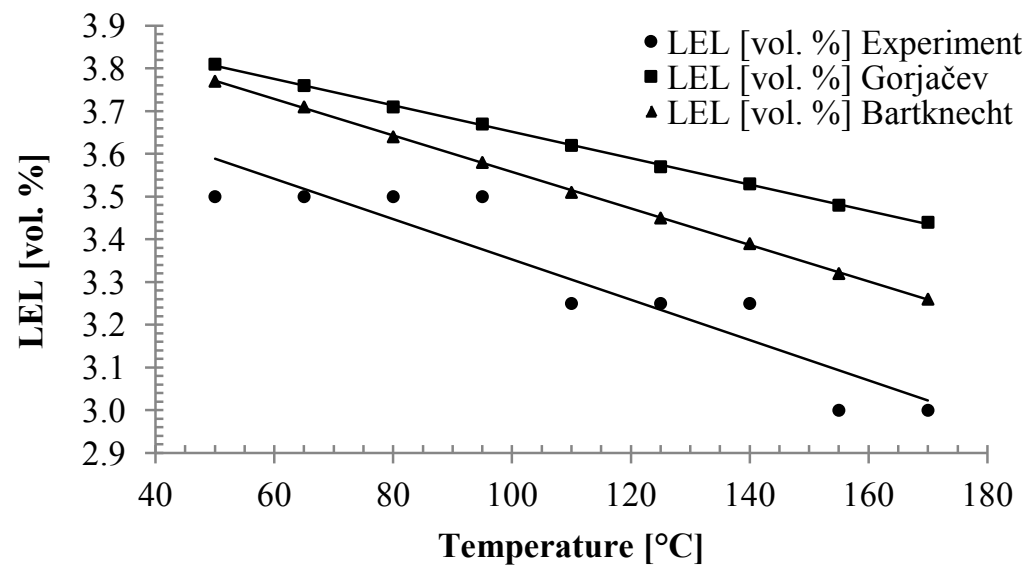

Figure 4: Graph of effect of temperature on lower explosive limit of industrial alcohol.

It can be noticed that the experimentally measured values are more similar to the values calculated by the equations of [1].

\subsubsection{Acetone}

The effect of temperature on lower and upper explosive limit of acetone is displayed in Figures 5 and 6. It is apparent from the graphs that, for given temperature interval, the experimentally determined values of upper explosive limit lie above the values calculated according to the empirical eqns (2) and (4). For lower explosive limit, decrease of experimental values is more significant than of values calculated from eqns (1) and (3). Values calculated according to

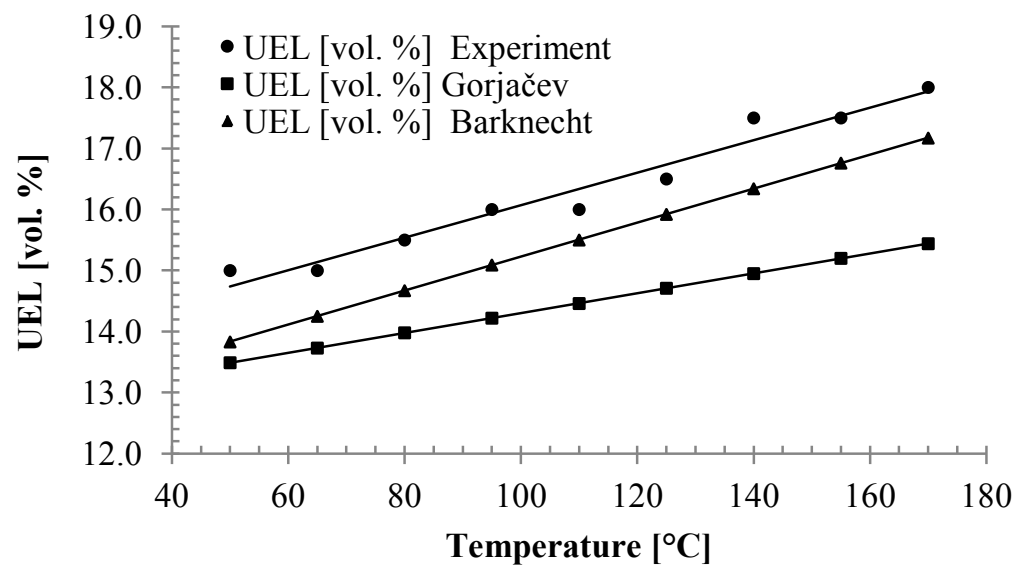

Figure 5: Graph of effect of temperature on upper explosive limit of acetone. 


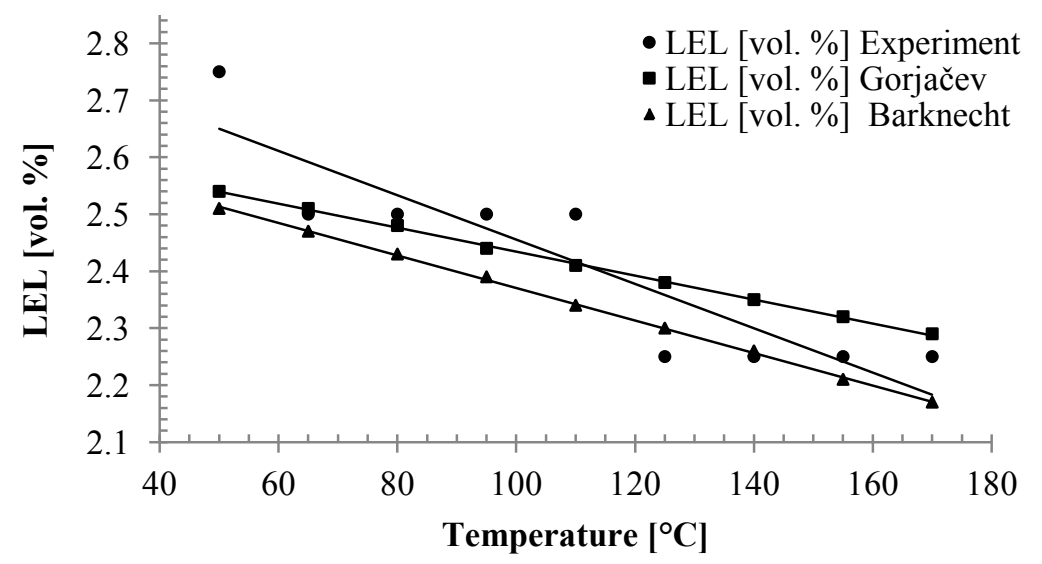

Figure 6: Graph of effect of temperature on lower explosive limit of acetone.

eqn (3) are situated below the experimentally determined values, it means out of the explosion range determined from the experimental values. For temperatures below $110^{\circ} \mathrm{C}$, values calculated according to eqn (1) are out of the explosion range. For temperatures above $110^{\circ} \mathrm{C}$, calculated values already occur within the explosion range.

\subsubsection{Toluene}

The effect of temperature on the upper and lower explosive limit of toluene is shown in Figures 7 and 8. The graphs show that the experimentally determined values of upper explosive limit in temperature interval are above values determined by empirical eqns (2) and (4). For lower explosive limit it can be

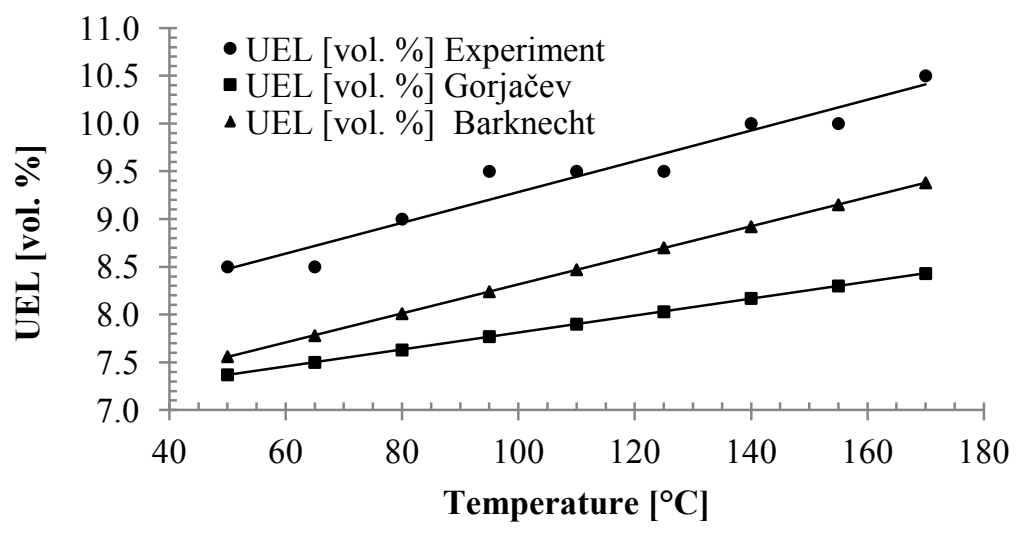

Figure 7: Graph of effect of temperature on upper explosive limit of toluene. 


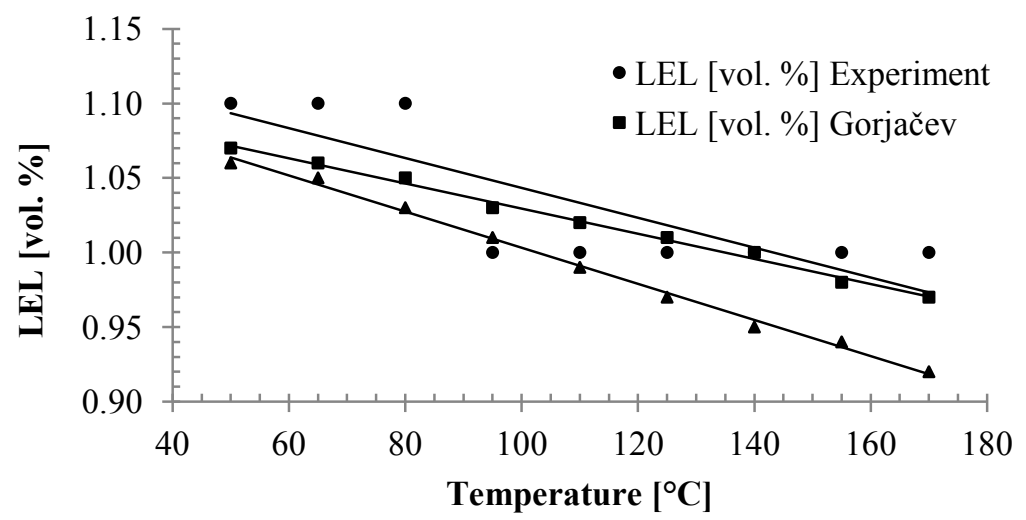

Figure 8: Graph of effect of temperature on lower explosive limit of toluene.

seen that calculated values from eqns (1) and (3) are below values determined by experiment and therefore they lie outside the explosion range determined from measured values.

\section{Conclusions}

The aim of this paper was to verify the effect of temperature on explosive limits of flammable liquids by experiment. Experimentally measured values were compared with values determined by empirical equations. The comparison of these values shows that the values differ, both in comparison of experimental data with empirical and also in comparison of data calculated by empirical equations of individual authors. Empirical equations can be therefore used only for an approximate determination of effect of temperature on explosive limits. To find the precise effect of temperature on explosive limits it is therefore preferable to take experimental measurements for the given flammable substance. That is also suitable because slopes of the lines describing the effect of temperature on explosive limits are different for various flammable liquids. Following the results, it is obvious that lower explosive limit decreases slower than upper explosive limit which increases sharply.

\section{References}

[1] Barktnecht, W. Explosion protection (in German). SpringerVerlag, Berlin, 1993

[2] Gorjačev, S. A., Kluban, V. S. Proceedings of "Fire prevention of technologic industrial process" (in Russian). VIPT MVD SSSR, Moscow, 1983

[3] Křenek, K. Verification of Calculation Methods of Determination of Temperature Influence on Concentration Explosion Limits by means of Experiment. Diploma thesis. Ostrava: VŠB - TU, 2012. 56 p. 